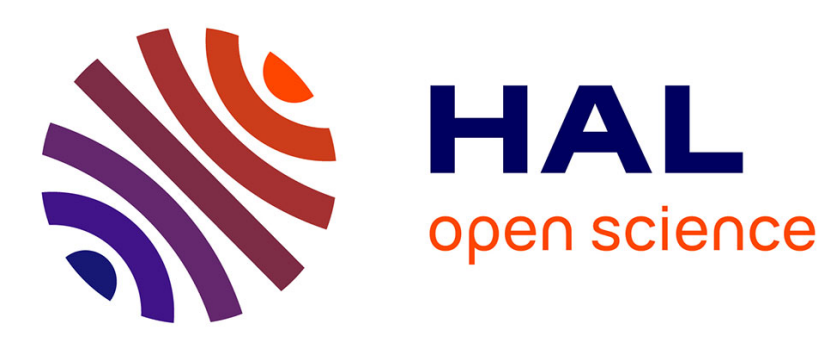

\title{
Materials Testing for Constitutive relations
}

\author{
D. Macdougall, J. Harding
}

\section{To cite this version:}

D. Macdougall, J. Harding. Materials Testing for Constitutive relations. Journal de Physique IV Proceedings, 1997, 07 (C3), pp.C3-103-C3-108. 10.1051/jp4:1997320 . jpa-00255477

\section{HAL Id: jpa-00255477 https://hal.science/jpa-00255477}

Submitted on 1 Jan 1997

HAL is a multi-disciplinary open access archive for the deposit and dissemination of scientific research documents, whether they are published or not. The documents may come from teaching and research institutions in France or abroad, or from public or private research centers.
L'archive ouverte pluridisciplinaire HAL, est destinée au dépôt et à la diffusion de documents scientifiques de niveau recherche, publiés ou non, émanant des établissements d'enseignement et de recherche français ou étrangers, des laboratoires publics ou privés. 


\title{
Materials Testing for Constitutive relations
}

\author{
D. Macdougall and J. Harding
}

Department of Engineering Science, University of Oxford, Parks Road, Oxford OXI 3PJ, U.K.

\begin{abstract}
High strain rate tests have been carried out at both room temperature and $100^{\circ} \mathrm{C}$ on a Ti6 Al4V alloy using the torsional split Hopkinson pressure bar. An infrared radiometer has been developed to measure the surface temperature of the specimen during the high speed torsional test. Data have been obtained on the variation of stress with strain and strain rate at shear strain rates from $0.0007 \mathrm{~s}^{-1}$ to $1000 \mathrm{~s}^{-1}$ and on the adiabatic temperature rise during deformation at the higher rates. This data has then been used to determine suitable values for the material constants in a constitutive relation of the form proposed by Zerilli-Armstrong for bcc materials for application to the hcp titanium alloy used in the present investigation.
\end{abstract}

Résumé : Des expériences à grandes vitesses de délormation ont été elíectuées à température ambiante et à $100^{\circ} \mathrm{C}$ sur l'alliage Ti6 Al4V, en utilisant des barres d'Hopkinson en torsion. Un radiomere intrarouge a été développé pour mesurer la température de surface de l'échantilion pendant le test. Des données ont été obtenues sur la variation de la contrainte en fonction de la vitesse de déformation et de la déformation, à des vitesses de glissement de $0.0007 \mathrm{~s}^{-1}$ à $1000 \mathrm{~s}^{-1}$ et sur l'élévation de température aux plus hautes vitesses. Ces données ont ensuite été utilisées pour déterminer le paramètres du matériau dans le modele de Zerilli-Armstrong, pour less matériaux de type cubique centré et ceux de type hexagonaux comme les alliages de titane.

\section{INTRODUCTION}

Numerical simulations are widely used to predict the response of complex structures to external impact loading. However, in order to have confidence in the results of such simulations, an accurate material model or constitutive relation is required. Until relatively recently it has been common to use very simple forms of constitutive relation. Thus in studies of the impact resistance of the leading edge of titanium alloy fan blades a rigid- perfectly plastic relationship was used in which allowance was made for the effect of strain rate on the plastic flow stress [1]. A more complex relationship which includes both plastic strain and temperature but remains empirical in form and is based on extensive material testing [2] has been used with some success to model the Taylor impact test on various $b c c$ and $f c c$ materials. Subsequently a semi-empirical constitutive relation, partly based on dislocation mechanics, has been proposed [3] and found to model even more closely the deformation in the Taylor impact test. Slightly different forms of this semi-empirical relation are employed for $b c c$ and $f c c$ materials. In a slightly modified version of its $b c c$ form the Zerilli-Armstrong relation has since been tested against its ability to model the high strain rate response of Remco iron in the tensile Hopkinsonbar test [4]. Slight discrepancies between experiment and numerical prediction observed in this work have subsequently been seen to arise from errors in the computer modelling.

The present paper is concerned with Ti6Al4V, a titanium alloy of $\boldsymbol{h c p}$ structure widely used in the manufacture of aero engines where the ability to withstand the ingestion of birds and accidental fan-blade release are two important aspects of aero engine safety. In order to predict the response of such complex stnuctures at high strain rates, the use of computer simulations has become widespread. To obtain realistic data from these simulations it is necessary to formulate an accurate constitutive relation which describes the material behaviour over a range of strains, strain rates and temperatures. Although in its original formulations the Zerilli-Armstrong relation was not developed for alloys of $h c p$ structure it has more recently been used to model the Taylor impact test on pure titanium specimens [5]. In the present study an attempt is made to evaluate its suitability for use with the Ti6Al4V alloy and to obtain the appropriate material constants.

In high-speed tension testing of Ti6 Al4 V alloy the early onset of necking instabifity severely limits the 
range of strains over which true stress-true strain data may be obtained $[1,6]$. In the present study, therefore the torsional split-Hopkinson pressure bar apparatus $[7,8]$ was used and tests were performed at nominal sheat strain rates of $600 \mathrm{~s}^{-1}$ and $1000 \mathrm{~s}^{-1}$. At high rates of strain, the heat generated by plastic work has insufficicn time to dissipate so some increase in temperature during the test may be expected. In an attempt to quantit! this effect, an infrared radiometer has been used [9] to measure the surface temperature of the test specinen during loading. Data obtained in this way has then been used to determine the material constants giving the best fit between the Zerilli-Armstrong relation and the high rate mechanical response of Ti6Al4V alloy.

\section{EXPERIMENTAL RESULTS}

\subsection{Stress-strain curves}

Shear stress-strain curves obtained using the torsional split-Hopkinson bar apparatus at room temperature and nominal shear strain rates of $600 \mathrm{~s}^{-1}$ and $1000 \mathrm{~s}^{-1}$ are compared with results obtained at a quasi-static rate of $0.0007 \mathrm{~s}^{-1}$ and an intermediate rate of $0.1 \mathrm{~s}^{-1}$ in figure 1. A test carried out at an elevated initial temperature of $100^{\circ} \mathrm{C}$ and a shear strain rate of $600 \mathrm{~s}^{-1}$ is also shown. Each curve is the average of three or more tests and is adjusted to an assumed value for the elastic shear modulus.

\subsection{Temperature measurement}

An infrared radiometer, full details of which are given elsewhere [9], was used to measure the surface temperature of the torsion specimens during uniform deformation in impact tests at $600 \mathrm{~s}^{-1}$ and $1000 \mathrm{~s}^{-1}$. Since the temperature rise is likely to be small during uniform deformation a large $\mathrm{HgCdTe}$ detector element, $1 \mathrm{~mm}$ square, was used. This is sensitive to radiation in the range $2 \mu \mathrm{m}-14 \mu \mathrm{m}$. To reduce thermal noise the detector was cooled with liquid nitrogen and to minimise optical distortion a Cassegrain-type optical

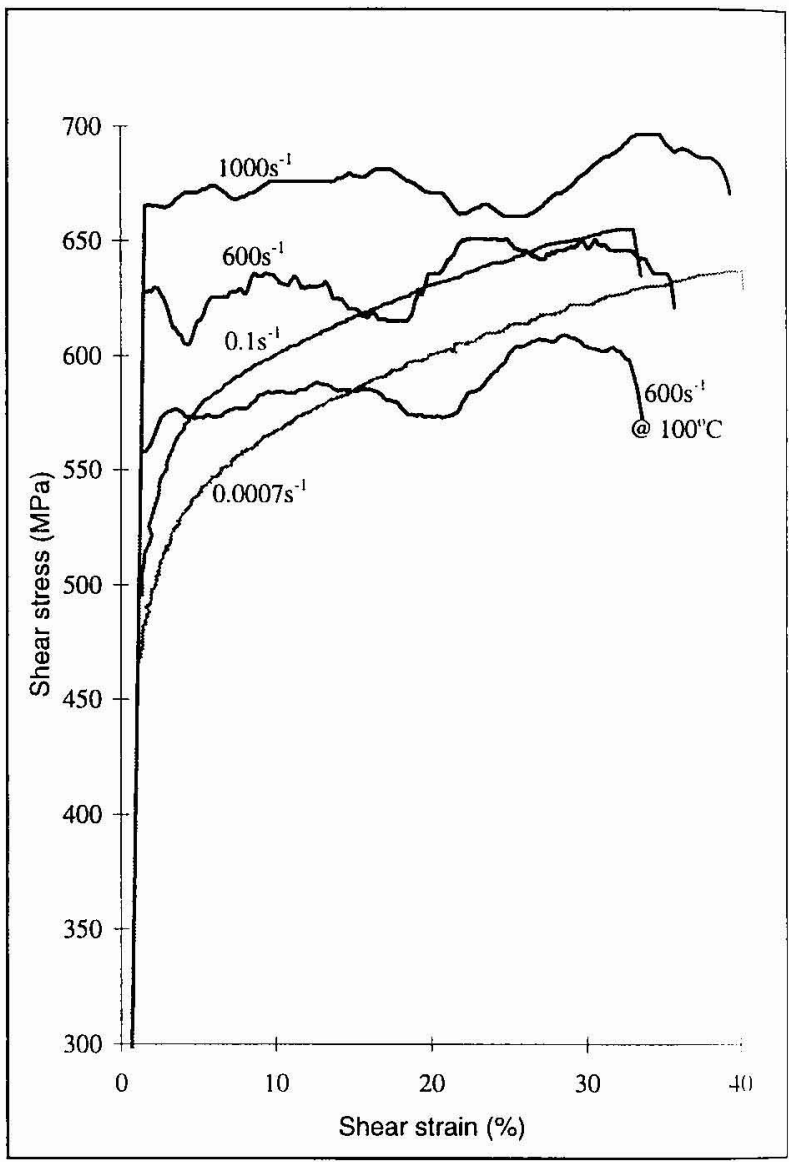

Figure 1 Stress-strain data for Ti-6Al-4V system was designed to focus radiation from the surface of the specimen onto the detector element. The distortion was approximately $\pm 12 \mu \mathrm{m}$.

The results of two tests at $600 \mathrm{~s}^{-1}$ in which the radiometer was used to determine the specimen surfice temperature with increasing plastic shear strain are shown in figure 2. The shear stress-plastic strain curve in the average for the two tests. It is apparent that the specimen temperature begins to rise early in the plastic region and has become quite significant before the localisation of plastic flow starts at approximately $40 \%$ plastic shear strain. From this point onwards the temperature in the specimen close to the region of localisation increases more rapidly and the single large detector element is only capable of measuring an average temperature over a longer length of specimen. However, using a 12-element detector with much smaller, $50 \mu \mathrm{m}$ square elements [10], temperatures of over $200^{\circ} \mathrm{C}$ have been measured near the point of fracture. 


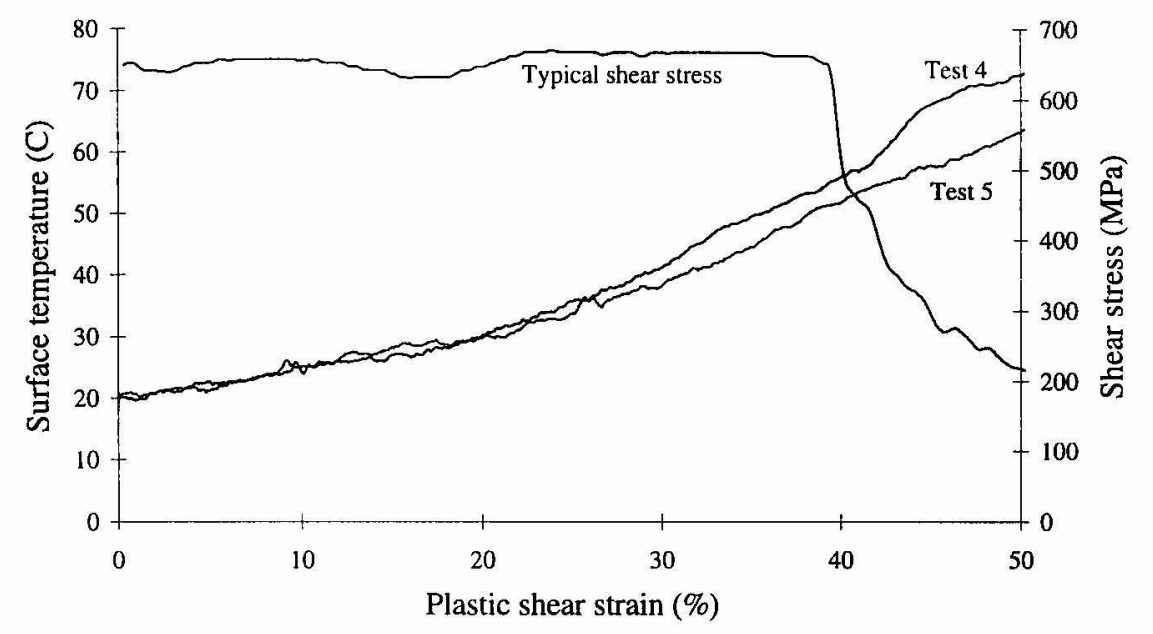

Figure 2 Shear stress and surface temperature during impact torsion tests at a shear strain rate of $600 \mathrm{~s}^{-1}$.

\section{CONSTITUTIVE RELATION}

\subsection{Zerilli-Armstrong b.c.c. constitutive relation}

The Zerilli Armstrong constitutive relation for $b c c$ metals has the form shown in (1)

$$
\sigma_{f}=\Delta \sigma_{G}+k \cdot l_{g d}^{-1 / 2}+B \cdot e^{-\left[\beta_{0}-\beta_{1} \cdot \ln (\dot{\epsilon})\right] \cdot T}+C \cdot \epsilon^{n}
$$

The first two terms are independent of temperature, strain rate and strain. The first is attributed to the effect of the initial dislocation density and the second is due to the hardening effect of grain boundaries. In this study they are combined in one athermal material constant, A, so that, in total, six material constants need to be determined, A, B, $\beta_{0}, \beta_{1}, C$, n.

\subsection{Derivation of material constants}

Since in the form shown the constitutive relation is a function of the effective stress and strain, it was necessary to convert the shear stress-strain data of figure 1 in terms of the von Mises yield surface, so that the effective stress and effective strain could be calculated from:

$$
\sigma_{e f f .}=\tau \cdot \sqrt{3} \quad \epsilon_{e f f .}=\frac{\gamma}{\sqrt{3}}
$$

By considering the variation of yield stress with strain rate at zero plastic strain the final term in (1) was omitted, leaving an equation for the yield stress, $\sigma_{Y}$,

$$
\sigma_{Y}=A+B \cdot e^{-\left[\beta_{0}-\beta_{1} \cdot \ln (\dot{\epsilon})\right] \cdot T}
$$

with the four constants, $A, B, \beta_{0}$ and $\beta_{1}$. Using the four values of yield stress obtained in room temperature tests at the four different strain rates two of these constants, $A$ and $\beta_{1}$ could be determined. The other two constants, $B$ and $\beta_{0}$, could then be derived from the yield stresses obtained in the tests at $600 \mathrm{~s}^{-1}$ at room 
temperature and $373 \mathrm{~K}$.

The remaining two material constants, $\mathrm{C}$ and $\mathrm{n}$, were derived by assuming the temperature to be constant during tests at the two quasi-static rates and by fitting the relation

$$
\sigma_{f}=\sigma_{Y}+C \cdot \epsilon^{n}
$$

to the work hardening curves which were almost identical in these two tests. The measure of agreement between the experimental measurements and equations (3) and (4) with the material constants derived in this way is shown in figures 3 and 4, for equations (3) and (4), respectively.

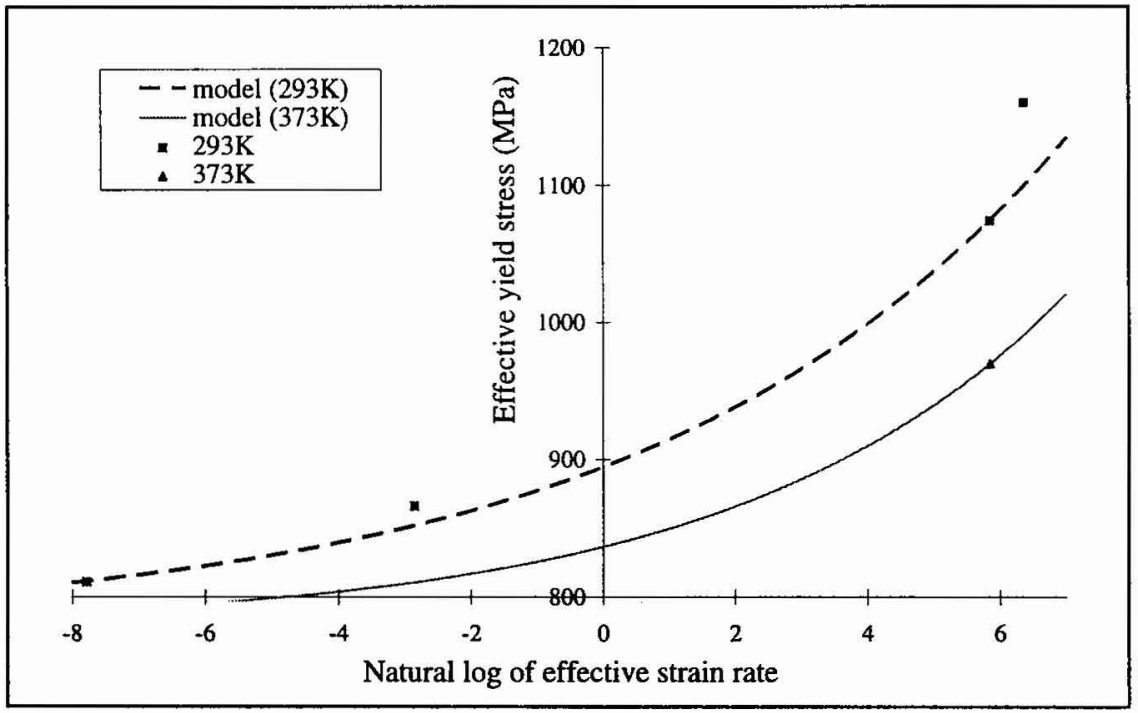

Figure 3 Strain rate dependence of yield stress: Model prediction and experimental data

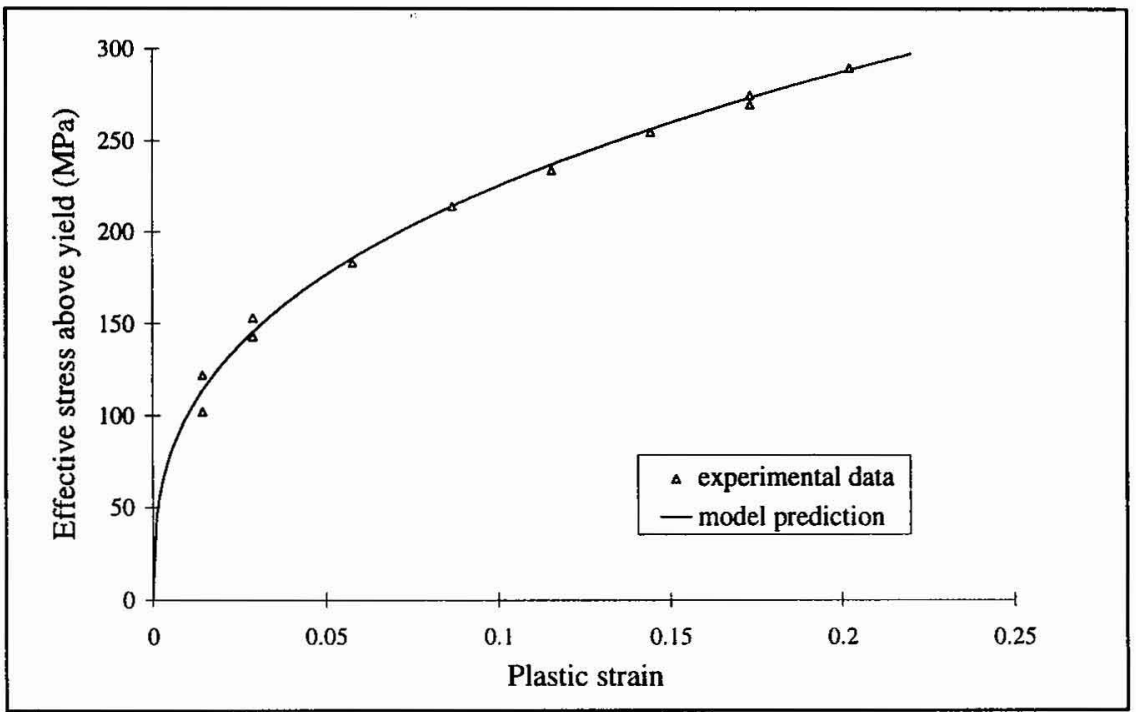

Figure 4 Quasi-static strain hardening: Model prediction and experimental data 


\section{VALIDATION OF PROPOSED CONSTITUTIVE RELATION}

A first test of the proposed constitutive relation is its ability to model the actual stress-strain response of the Ti6Al4V alloy in the high strain rate torsional tests where there was a measured increase in the specimen temperature during the test and where the rate of work hardening was found, see figure 1, to be negligibly small. Using the material constants quoted in Table I and taking the changing specimen temperature from the

Table I Derived Material Constants

\begin{tabular}{|c|c|c|c|c|c|}
\hline $\mathrm{A}$ & $\mathrm{B}$ & $\beta_{0}$ & $\beta_{1}$ & $\mathrm{C}$ & $\mathrm{n}$ \\
\hline $778 \mathrm{MPa}$ & $1465 \mathrm{MPa}$ & $0.00864 \mathrm{~K}^{-1}$ & $0.000546 \mathrm{~K}^{-1}$ & $508 \mathrm{MPa}$ & 0.3529 \\
\hline
\end{tabular}

data in figure 2 a predicted effective stress-strain curve was obtained equivalent to a torsional test at $600 \mathrm{~s}^{-1}$. A comparison between the experimental and the predicted curves is given in figure 5 . The predicted curve progressively overestimates the actual flow stress as the plastic strain increases and does not show the very low work hardening rate observed in the experimental curve. It is clear that the relatively small increase in temperature resulting from the high rate deformation, which reduces the second term in (3) is insufficient to eliminate the work hardening response, given by the second term in (4). Furthermore, the required increase in temperature during the test for the reduction in the second term in (3) to be sufficient to cancel the work hardening term in (4) is of the order of 250 to $300^{\circ} \mathrm{C}$, well above any possible margin of error in the temperature measuring system and much greater than that which might be expected even if all the mechanical work was converted to heat.

It must be concluded that in the form given in (1), where the work hardening term is assumed to be independent of both temperature and strain rate, the Zerilli-Armstrong relation cannot describe the mechanical response of Ti6Al4V at impact rates of strain. However, in a version of the Zerilli-Armstrong relation, [11], a temperature dependence of the work hardening constant, $\mathrm{C}$, as has been proposed when it is applied to high rate deformation of $\boldsymbol{b c c}$ iron. An attempt to use the same approach here, while reducing the overshoot in the predicted stress levels, does not model the very low rate of work hardening. A more successful, although entirely empirical, approach is to use a much reduced, but constant, value for $\mathrm{C}$ in the high rate tests. Thus giving $\mathrm{C}$ the value of $150 \mathrm{MPa}$ for the test at $600 \mathrm{~s}^{-1}$ leads to a predicted curve, shown in figure 5 , lying very

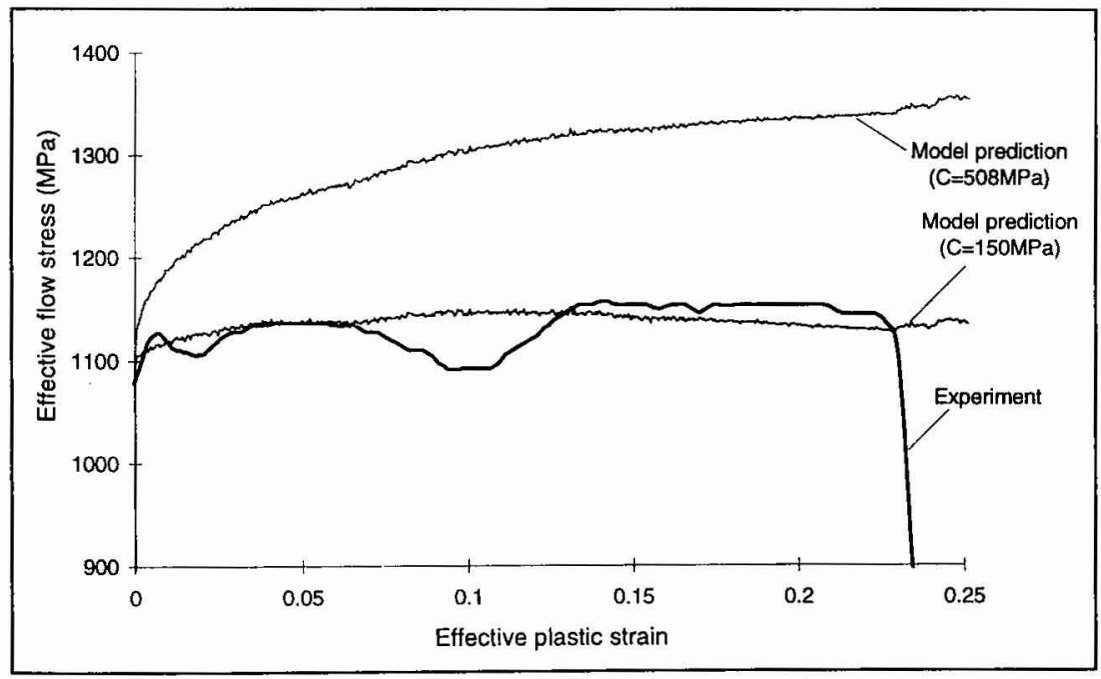

Figure 5 Comparison of experimental and predicted flow stress 
close to the experimental result. This is purely a curve-fitting exercise and a more scientific basis remain. 10 be established. Meanwhile a more stringent test of the present relation will be its ability to predict the stres, strain response, including the reduction in area and localised temperature rise due to necking, in tensile impict tests on the same Ti6Al4V alloy. This will be the subject of a further paper.

\section{CONCLUDING REMARKS}

Torsional stress-strain curves have been obtained for Ti6Al4V alloy at room temperature and four strain rates. from $0.0007 \mathrm{~s}^{-1}$ to $1000 \mathrm{~s}^{-1}$, and at $100^{\circ} \mathrm{C}$ and $600 \mathrm{~s}^{-1}$. The increase in specimen temperature during the room temperature tests at the two higher rates has been determined. Using this data material constants have bein obtained which allow the Zerilli-Armstrong constitutive relation, in the form applicable to bcc materials, 10 be fitted to the experimentally determined rate and temperature dependence of the yield stress and to the quasi-static work hardening rate. Using these constants it is found that the Zerilli-Armstrong constitutive relation is unable to predict the marked reduction in work hardening rate observed in the high rate torsion tests without some modification to the work hardening term at the higher strain rates.

\section{Acknowledgements}

This work was supported by the ESPRC under grant No. GR/J/46036. Grateful acknowledgment is also made to Rolls Royce Ltd., Derby for supplying the test material.

\section{References}

[1] Noble J. P. and Hughes D. A., DYMAT $7^{\text {th }}$ Technical Conference, ISL Saint Louis, (1992) pp.8.1-8.10

[2] Johnson G. R. and Cook W. H., in Proc $7^{\text {th }}$ Int. Symposium on Ballistics, The Hague, Netherlands, (1983).

[3] Zerilli F. J. and Armstrong R. W., J. Appl. Phys., Vol. 61, No. 5 (1987)

[4] Noble J. P. and Harding J., in Proc EURODYMAT 94, Jour de Physique III, No. 9, Vol. 4, Colloque 8. (1994), pp. 477-482

[5] Holt W. H., Mock W., Zerilli F. J. and Clark J. B., Mechanics of Materials, vol. 17, (1994), pp. 195-201.

[6] Hughes D. A., Ruiz C. and Martindale I., in Proc. EURODYMAT 94, Jour de Physique III, No. 9 , Vol. 4, Colloque 8, (1994), pp. 565-570.

[7] Macdougall D. A. S. and Harding J., in Proc EXPLOMET 95, Elsevier Science B. V., (1995), pp. 909-916

[8] Xue Q., Shen L. T. and Bai Y. L., Meas. Sci. Tech., vol. 6, (1995), pp.1557-65.

[9] Trojanowski A., Macdougall D. A. S. and Harding J., (in preparation)

[10] Macdougall D. A. S. and Harding J., (in preparation)

[11] Goldthorpe, B. D., in Proc DYMAT 91, Jour de Physique III, No. 1, Vol. 8, Colloque C3, (1991), pp. 829-835. 